Numbers of patients with occupations indicating high degree of exposure to chemicals in 88 men with Hodgkin's disease (HD) and three control groups. (See text for description of controls)

\begin{tabular}{|c|c|c|c|c|c|}
\hline & & \multirow{2}{*}{$\begin{array}{c}\text { Patients } \\
\text { with } \\
\text { HD } \\
(\mathbf{n}=\mathbf{8 8})\end{array}$} & \multicolumn{3}{|c|}{ Control groups } \\
\hline & & & $\begin{array}{c}A \\
(n=100)\end{array}$ & $\begin{array}{c}B \\
(n=100)\end{array}$ & $\begin{array}{c}C \\
(n=32)\end{array}$ \\
\hline 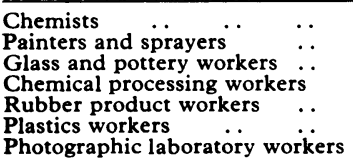 & $\begin{array}{l}\ldots \\
\because \\
\because \\
\cdots \\
\cdots \\
\cdots\end{array}$ & $\begin{array}{l}2 \\
5 \\
5 \\
1 \\
2 \\
1 \\
1\end{array}$ & 1 & $\begin{array}{l}1 \\
1\end{array}$ & 1 \\
\hline
\end{tabular}

occupations in the working male population in Sweden. The results therefore suggest that exposure to some chemical agents may be important for the development of HD.

Interestingly, occupational exposure was uncommon in the patients with HD aged $20-30$ years, whereas among the older patients $26-32 \%$ were occupationally handling chemicals. The incidence curve of HD is bimodal, with one peak between 20 and 30 years of age and a second increase beginning about the age of 35 years. This may be due to differences in aetiology between various age groups. ${ }^{3}$ Our results indicate that occupational exposure to chemical oncogenic agents may be of some importance for the development of HD in men aged over 30, whereas other aetiological factors may be more important in the younger age groups.

We emphasise that occupational titles obtained from case records will give only crude and insufficient information on occupational hazards. Despite this shortcoming, our finding of occupational exposure to chemicals in about $20 \%$ of adult men with $\mathrm{HD}$ means that efforts should be made to define environmental hazards that may be important in the development of HD. Such studies are in progress at our department.

This work was supported by grants from the Swedish Cancer Society.

1 Olin, R, Lancet, 1976, 2, 916.

2 Statistical Abstract of Sweden 1976, vol 63. Stockholm, National Central Bureau of Statistics, 1976.

MacMahon, B, Cancer Research, 1966, 26, 1189.

(Accepted 27 fune 1979)

Department of Oncology, University Hospital, S-221 85 Lund, Sweden

H OLSSON, MD, research fellow

L BRANDT, MD, associate professor of internal medicine

\section{Who wants to sit on the GMC?}

What makes an individual ambitious for power? Is it inborn or is it forced on us by environmental circumstances?

An unusual opportunity to examine the question arose recently in that mind-numbing list of 150 doctors wishing to represent England on the General Medical Council. It arrived on a hot afternoon, and the natural reflex to throw this bundle of paper away was inhibited first by inertia and then by a nagging curiosity. Who were these people who wished to assert themselves in Hallam Street, and what distinguished them from the rest of us-those meek and apathetic doctors whom they expected to vote for them ?

The least demanding epidemiological approach was to examine the one quantitative variable they presented: their year of birth. It was at once apparent that this was no ordinary distribution: throughout the range from 1911 to 1952 periods of three or four years with many candidates were followed by two to three years with very few in a remarkably regular pattern. That one of the more vociferous representatives of a national organisation should have been born in a peak year when the year of birth of one of us two years later was in a quiescent trough was enough to clinch the matter. A more formal statistical approach seemed necessary, however, to convince the sceptical.

The data were examined by spectral analysis of the serial correlations between birth frequencies for intervals of $1,2,3, \ldots$ years. The serial correlations showed an undulatory pattern with peaks corresponding to about six-year intervals, and the cyclicity was confirmed by the peak in the periodogram (figure).

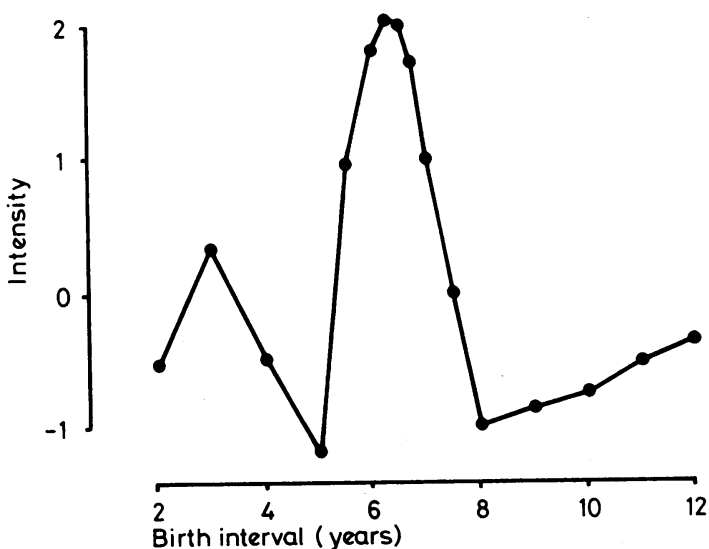

Periodogram showing cyclicity of birth data on GMC candidates. The intensity is a Fourier transform of serial correlation coefficients.

We offer this observation as the basis for a $\mathrm{PhD}$ thesis on the cyclical nature of medical aspirations. What happens in a regular sixor seven-year cycle to account for recurrent crops of politicians? Many comets have a periodicity of between six and seven years, but the data suggest a more gradual ebb and flow of influence, and there may be the basis here for making astrology respectable.

(Accepted 23 August 1979)

Clinical Research Centre, Harrow, Middlesex HA1 3UJ

F E HYTTEN, MD, FRCOG, head, division of perinatal medicine J P ROYSTON, MSC, MIS, statistician, division of computing and statistics

\section{Pindolol and pulmonary fibrosis}

Of the beta-blocking agents used in clinical medicine practolol has been especially associated with adverse reactions. A lupus-like syndrome, ocular and skin disease, sclerosing peritonitis, deafness, nephrotic syndrome, joint effusion, pleural effusion, pulmonary fibrosis, ${ }^{1}$ and pleural fibrosis ${ }^{2}$ have been described. We present a patient who developed pulmonary fibrosis during treatment with a related beta-blocker, pindolol.

\section{Case report}

A 55-year-old man, a lecture-room projectionist, who smoked 15-20 cigarettes daily presented in December 1978 with a three-month history of progressive exertional dyspnoea and non-productive cough. He had been treated with pindolol for seven years for essential hypertension. His pulse rate was $82 / \mathrm{min}$ and his blood pressure $150 / 90 \mathrm{~mm} \mathrm{Hg}$. He had tachypnoea, respiratory crepitations in both mid and lower zones, but no finger clubbing. Dressing and walking 20-30 metres briskly on level ground induced dyspnoea. Chest radiographs showed small irregular opacities throughout both lung fields without pleural abnormality. A chest radiograph four years previously had been normal. Results of laboratory investigations included: erythrocyte sedimentation rate $40 \mathrm{~mm}$ in $1 \mathrm{~h}$; haemoglobin concentration $14.9 \mathrm{~g} / \mathrm{dl}$; leucocyte count $6.8 \times 10^{\circ} / 1$ with normal differential count; and no rheumatoid or antinuclear factors found. Forced expiratory volume in one second was $73 \%$ of predicted and forced vital capacity $63 \%$ of predicted. Total lung capacity was $70 \%$ of predicted, single breath carbon monoxide transfe factor $65 \%$ of predicted, and the ratio of transfer factor to effective alveolar volume $93 \%$ of predicted.

At thoracotomy the pleural surface of the left lung appeared granular and the lung substance felt rubbery. A wedge-shaped biopsy specimen from the posterior aspect of the left upper lobe showed patchy changes on microscopy (figure). In some areas closely packed sheets of desquamated cells filled alveoli and were within small airways, many containing PAS-reactive material (resistant to earlier diastase digestion). Alveolar septa were patchily thickened by fibrous tissue and there were varying amounts of cuboidal change, atypia, and syncytial arrangements of alveolar lining cells. Inflammatory changes were mild to moderate with an infiltrate of mononuclear cells in the fibrous tissue and the walls of the damaged bronchioles. The walls of some small pulmonary arteries showed mild thickening. There was 
no appreciable interstitial smooth muscle proliferation. Electron microscopy showed variable thickening of alveolar septa with a few smooth muscle fibres present between the collagen fibres. Type II pneumocytes were prominent. No foreign material was detected.

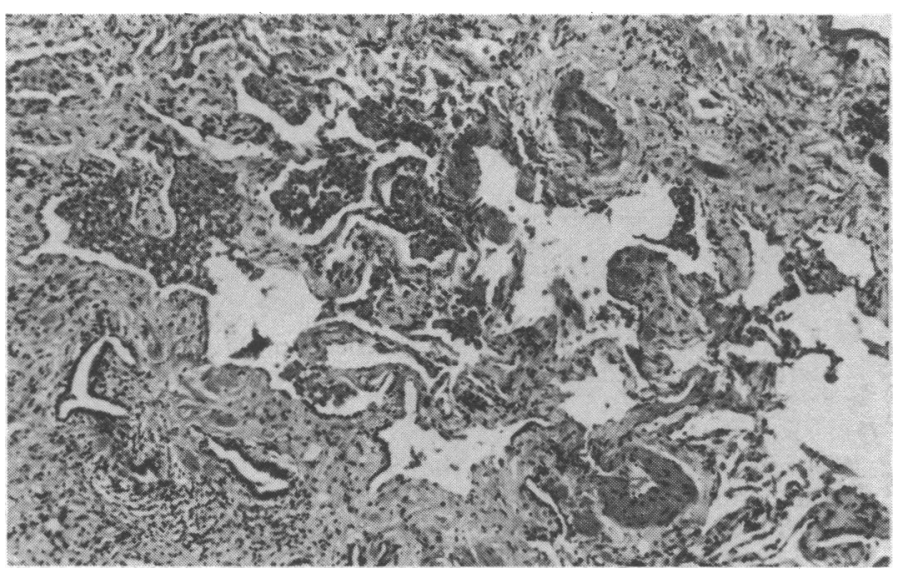

Area of lung showing collections of desquamated cells, interstitial fibrosis, chronic inflammation, and thick-walled arteries. Haematoxylin and eosin $\times 100$ (original magnification).

\section{Comment}

There was no history of inhaled extrinsic fibrogenic material or ingestion of other drug or toxin and no evidence of systemic disease. A diagnosis of "classical" cryptogenic fibrosing alveolitis was unlikely in the absence of finger clubbing. A similar pulmonary reaction occurs after treatment with practolol ${ }^{1}$ but has not been reported with pindolol. Practolol and pindolol are structurally different from propranolol, oxprenolol, and alprenolol in having a nitrogen atom attached to an aromatic ring, producing a stereochemical configuration similar to methysergide which is well known to produce fibrosing reactions. ${ }^{3} \mathrm{~A}$ common stereochemical structure may be implicated in the fibrosing reactions induced by these drugs.

1 Erwteman, T M, Braat, M C P, and Van Aken, W G, British Medical Fournal, 1977, 2, 297.

2 Hall, O R, Morrison, J B, and Edwards, F R, Thorax, 1978, 33, 822.

3 Griffiths, $\mathbf{R}$ W, et al, in Toxicological Considerations in Ergot Alkaloids and Related Compounds, ed B Berde and H O Schild, p 805. New York, Springer-Verlag, 1978.

(Accepted 6 fuly 1979)

Departments of Respiratory Medicine and Pathology, Queen

Elizabeth II Medical Centre, Nedlands, Western Australia 6009

A W MUSK, MB, FRACP, physician in respiratory medicine

J A POLLARD, MB, FRCPA, senior registrar in histopathology

\section{Slow drug infusions using a portable syringe driver}

Motor-driven syringes, often called "syringe pumps," have been available for many years for the slow infusion of drugs, but, until recently, they have mostly been cumbersome, expensive, mainsoperated machines suitable only for bedridden patients. Most drugs that are now injected periodically would probably be better infused slowly because the blood concentration could be kept in the desired range instead of being much of the time either above or below it. Slow infusions also avoid the disturbance of the patient and the work for the nurses of periodic injections, especially at night. Their scope, however, is limited if used only for bedridden patients, so a portable instrument is clearly essential. In this paper we describe such a device, its mode of use, and performance.

\section{Machine, method, and results}

The instrument (figure) is a compact unit measuring $166 \times 53 \times 23 \mathrm{~mm}$ and weighing, with battery, $175 \mathrm{~g}$. The syringe is driven by a bracke riding on a lead screw which is rotated intermittently by a battery-operated motor in response to pulses from an electronic timer. The pulse intervals may be varied by two decade switches to give driving rates from $1-99 \mathrm{~mm} / \mathrm{h}$. With a $10-\mathrm{ml}$ syringe each pulse delivers about $0.01 \mathrm{ml}$, and the pulse intervals vary from a few seconds to several minutes. A PP3 alkaline battery gives a running life of about three months. A shoulder holster is provided for carrying the driver under the clothing, where it is invisible and well

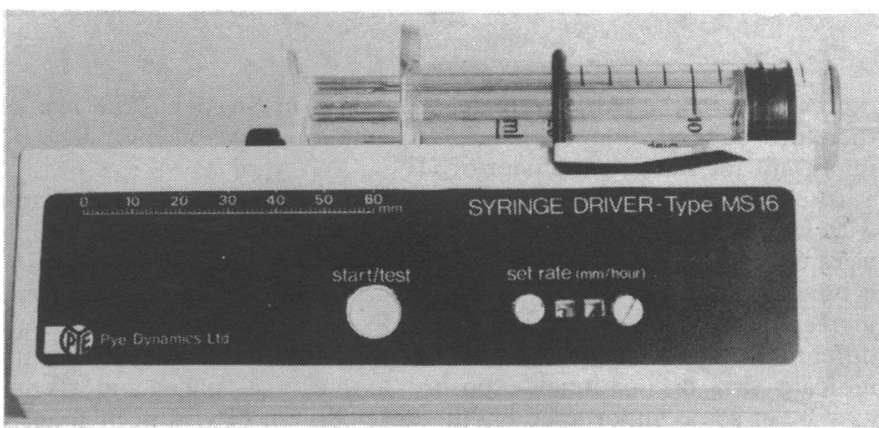

Front view of syringe driver showing controls.

protected. Because it will take almost any syringe the driver is calibrated in $\mathrm{mm} / \mathrm{h}$ and not $\mathrm{ml} / \mathrm{h}$. The driving rate must therefore be calculated by dividing the required length of travel of the piston (measured against a mm scale on the instrument) by the time of delivery in hours. For routine use the dose can be made up to a standard volume so that the rate for a given period is always the same. The rate is set with a screwdriver or similar object in the slotted spindles of the decade switches. These and the starting button are flush, so they cannot be accidentally operated and can be taped over if required.

So far the driver has been used mainly in treating thalassaemia with a daily 12-hour subcutaneous injection of desferrioxamine. More than 1000 instruments have been in use for this purpose in the past year. Since most of the patients are children or adolescents, many in relatively undeveloped countries, this has provided good evidence of the reliability and acceptability of the device. ${ }^{1}$ It has also been used in this and other hospitals for heparin infusions, cancer chemotherapy, scalp-vein transfusions, milk feeds, postoperative analgesia, ${ }^{2}$ and domiciliary analgesia in terminal cancer, ${ }^{3}$ and for giving neostigmine in cases of myasthenia gravis.

\section{Comment}

Because of the small volume injected at each pulse nearly all drugs can be given subcutaneously or intramuscularly, the slower absorption being unimportant with a slow infusion. Subcutaneous needles may be left in situ for weeks at a time ${ }^{34}$ and the subcutaneous and intramuscular routes are much safer than the intravenous, making possible domiciliary treatment by a community nurse. The device is, we believe, substantially smaller, simpler, cheaper, and more versatile than any other of its kind available. But we expect, and hope, that such syringes will soon become commonplace and will make slow infusion of drugs a routine procedure.

We thank our colleagues in the Clinical Research Centre and Northwick Park Hospital for their interest and encouragement. The instrument developed from a prototype designed and made by us, is being made and marketed by Pye Dynamics Ltd, Bushey, Herts, and we thank them for their co-operation in its development. The National Research Development Corporation has applied for a patent (BPA No 9947/77).

1 Pignatti, C B, and de Stephano, P, British Medical fournal, 1978, 2, 1432. 2 Davenport, H T, and Wright, B M, British Medicalfournal, 1979, 1, 1561 3 Russell, P S B, British Medical fournal, 1979, 1, 1561.

4 Bingle, J P, Rutherford, J D, and Woodrow, P, British Medical fournal, $1979,1,1050$

(Accepted 11 fuly 1979)

Clinical Research Centre, Northwick Park Hospital, Harrow, Middlesex HA1 3UJ

B M WRIGHT, MA, MB, visiting worker

K CALLAN, senior research officer 